\title{
Predicting the effect of climate change on temperate shallow lakes with the ecosystem model PCLake
}

\author{
W. M. Mooij - J. H. Janse - L. N. De Senerpont Domis · \\ S. Hülsmann · B. W. Ibelings
}

(C) Springer Science+Business Media B.V. 2007

\begin{abstract}
Global average surface temperatures are expected to rise by about $1.4-5.8^{\circ} \mathrm{C}$ from the present until the year 2100. This temperature increase will affect all ecosystems on earth. For shallow lakes-which can be either in a clear water or a turbid state-this climate change will expectedly negatively affect water transparency though the prediction is far from conclusive and experimental investigations elucidating the potential climatic effects on shallow lakes are still rare. The aim of this study was to further shape and sharpens hypotheses on the impact of climate change on shallow lakes by applying an existing and well-calibrated ecosystem model, PCLake. We focused on asymptotic model behaviour for a
\end{abstract}

Guest editors: R. D. Gulati, E. Lammens, N. De Pauw \& E. Van Donk

Shallow lakes in a changing world

W. M. Mooij $(\varangle)$ · L. N. De Senerpont Domis .

B. W. Ibelings

Netherlands Institute of Ecology, Centre for

Limnology, Rijksstraatweg 6, 3631 AC Nieuwersluis,

The Netherlands

e-mail: w.mooij@nioo.knaw.nl

J. H. Janse

Netherlands Environmental Assessment Agency, P.O. Box 303, 3720 AH Bilthoven, The Netherlands

S. Hülsmann

Institute of Hydrobiology, Dresden University

of Technology, 01062 Dresden, Germany range of temperature and loading scenarios in a factorial design. We conclude that climate change will likely lead to decreased critical nutrient loadings. Combined with an expected increase in the external nutrient loading, this will increase the probability of a shift from a clear to a turbid state. As the model predicts a higher summer chlorophyll-a concentration, a stronger dominance of cyanobacteria during summer and a reduced zooplankton abundance due to climate change, the turbid state itself is likely to become even more severe.

Keywords Temperature - Alternative stable states · Critical nutrient loading - Cyanobacteria . Mismatch

\section{Introduction}

Global average surface temperatures have increased by approximately $0.6^{\circ} \mathrm{C}$ over the last century (Houghton et al., 2001). Without proper action against anthropogenic greenhouse effects the Intergovernmental Panel on Climate Change (IPCC) predicts increases in global surface temperature of $1.4-5.8^{\circ} \mathrm{C}$ for the year 2100 (Houghton et al., 2001). Ecological responses to recent climate warming have been demonstrated across different natural systems (Pace, 1984; Parmesan \& Yohe, 2003), including temperate 
lakes (Straile \& Adrian, 2000; Gerten \& Adrian, 2002). Because of their smaller volume and absence of stratification in summer, shallow water bodies are less influenced by meteorological conditions in the preceding winter than deeper waterbodies, and they respond more directly to prevailing weather conditions (Gerten \& Adrian, 2001).

Of the many aspects of shallow lake ecosystems on which climate can have an impact, water transparency is of particular interest to water quality managers and this parameter has often been used to evaluate the success of restoration measures (Drenner \& Hambright, 1999; Gulati \& Van Donk, 2002). According to the concept of alternative stable states (Scheffer et al., 1993), switches between a macrophyte-dominated clearwater state and a phytoplankton-dominated turbid state occur abruptly in shallow lakes when (external) nutrient loading passes a certain critical level. However, even phytoplankton-dominated lakes may have temporary clear-water phases, which are typically caused by enhanced grazing pressure on phytoplankton by zooplankton at the end of the spring (Gulati et al., 1982; Sommer et al., 1986).

In a recent review of the potential impact of climate change on shallow lakes in the Netherlands (Mooij et al., 2005) it is concluded that climate warming will probably negatively affect transparency in shallow lakes. It is expected that climate warming will tend to destabilize the macrophyte-dominated clear state, stabilize the phytoplankton-dominated turbid state and hamper the recolonization of the lake by macrophytes under the current management regime (Mooij et al., 2005). These expectations rest on a number of assumptions. (1) The expected increase of net precipitation in winter, and especially an increase in extreme rainfall events, will tend to increase the P-loading of lakes (Mooij et al., 2005). (2) Internal nutrient loading will increase with temperature (Jensen \& Andersen, 1992; Liikanen et al., 2002). (3) Elevated temperature may cause a mismatch between the timing of the phytoplankton spring peak and the zooplankton spring peak (leading to a reduced grazing pressure on phytoplankton) if both peaks are triggered by different stimuli which might be the case when daphnids establish themselves mainly from resting eggs (Winder \& Schindler, 2004). (4) Elevated temperatures will favour cyanobacteria and in turn lead to a further decoupling of phytoplankton and zooplankton growth because cyanobacteria are known to be a relatively poor food item for zooplankton (Dawidowicz et al., 1988; Gliwicz \& Lampert, 1990). (5) Zooplanktivory by fish will increase due to decreased winter mortality and higher recruitment (Mooij, 1996; Mehner et al., 1998; Mooij \& Van Nes, 1998; Nyberg et al., 2001). (6) Sediment resuspension by wind (Schelske et al., 1995) will increase. Jeppesen et al. (2003) reach similar conclusions for Danish shallow lakes. If all or some of these assumptions are correct, this implies that the effects of climate change on shallow lakes will mimic the effects of eutrophication, as has indeed been predicted by some authors (Kilham et al., 1996; Porter et al., 1996).

It has to be noted, however, that the anticipated negative effects of climate change on lake transparency are still far from being conclusive, since counteracting effects seem possible, for instance high $\mathrm{P}$ loading of inflowing water might (temporarily) be balanced by dilution effects when net precipitation is increased; increased internal loading might be a transient phenomenon; a mismatch between phytoplankton and zooplankton has only been described for deep lakes and is related to stratification patterns, which might not apply to shallow lakes; enhanced growth rates of cyanobacteria may in case of scum forming species be counteracted by disturbing effects of wind and increased cloud cover (Howard \& Easthope, 2002); macrophytes positively respond to increasing temperature (Barko \& Smart, 1981; Rooney \& Kalff, 2000), which could result in a stabilization of the clear water state.

Experimental approaches to potential climatic effects on shallow lakes are still rare (see below) or underway (Liboriussen et al., 2005) and so far only systems mimicking the macrophyte-dominated clear water state have been studied. Results of an enclosure experiment in two subsequent years with different summer temperatures suggest that at critical nutrient loading levels, a switch from the clear to the turbid state is more likely to occur in years with warmer summers (Van de 
Bund et al., 2004). Studies using outdoor microcosms (McKee et al., 2002a, b, 2003; Moss et al., 2003) indicate, however, that direct temperature effects on lakes in a clear state dominated by macrophytes may be subtle and that warming does not significantly encourage phytoplankton blooms, even in combination with increased nutrient levels and fish densities. Nevertheless, warming produced trends in water chemistry that support the idea that even moderate warming has the potential to exacerbate existing eutrophication problems (Moss et al., 2003). This may, at least in the long run, destabilize macrophyte dominated clear-water states (e.g. Van de Bund \& Van Donk, 2002).

Model analysis may help to further shape and sharpen hypotheses on the impact of climate change on shallow lakes and thereby provide a good starting point for further empirical work (e.g. time series analysis, mesocosm experiments). Specific aspects such as shifts in the phenology of phytoplankton and zooplankton in spring may be studied with relatively simple models such as the seasonally forced predator-prey model of Scheffer et al. (1997). Recently, a more detailed phytoplankton model was linked with a climate model by Elliott (2005) using historical data. For a more comprehensive view of the impact of climate change that includes effects of internal and external nutrient loading as well as (at least some) feedback mechanisms within the system, we argue that there is a need for analysis using a full scale ecosystem model such as PCLake (Janse, 2005). Although such ecosystem models are widely used to evaluate the effects of eutrophication, we know of no study that applies such models to predict the impact of climate change. The purpose of this study was to initiate the analysis of the potential effects of climate change on shallow lakes by means of a comprehensive ecosystem model.

We designed our study to cover some of the central aspects of the interaction between the functioning of shallow lakes and climate change: (1) increasing water temperature will affect abiotic process rates in the lake water and sediment, including internal loading; (2) increasing temperature will affect the physiology and life history of the biotic components of the ecosystem; and (3) climate change will lead to increased external nutrient loading, in particular through an increase in winter precipitation. To cover these three aspects we ran the model for four temperature scenarios (including a control scenario) and a wide range of external nutrient loadings. We initiated the model in both the clear state and the turbid state to scan for multiple stable states and to determine the critical nutrient loading of the switch from clear to turbid during eutrophication $\left(\mathrm{CNL}_{\mathrm{eu}}\right)$ and from turbid to clear during lake restoration, i.e. (re)oligotrophication $\left(\mathrm{CNL}_{\text {oligo }}\right)$.

\section{Methods}

The ecosystem model PCLake used in our study of the effects of climate change was developed to study the effects of eutrophication and related restoration measures in shallow lakes (Janse et al., 1992; Janse \& Van Liere, 1995a, b). The model has been designed to simulate the main nutrient and food web dynamics of a nonstratifying lake (Janse, 1997, 2005). It was calibrated against nutrient, transparency, chlorophyll and vegetation data on $>40$ lakes, and a systematic sensitivity and uncertainty analysis was recently performed (Aldenberg et al., 1995; Janse, 2005).

The model describes a completely mixed water body and comprises both the water column and the sediment top-layer $(10 \mathrm{~cm})$, with the most important biotic and abiotic components. No further horizontal or vertical distinction within the lake is taken into account. Optionally, a wetland zone with marsh vegetation may be included, but this has not been done in this study. Mathematically, the model is composed of a number of coupled differential equations, one for each state variable. All biota are modelled as functional groups. The main groups in the water phase are 3 prototypic groups of phytoplankton ("diatoms", "greens" and "cyanobacteria"), zooplankton, planktivorous/benthivorous fish and piscivorous fish. Submerged macrophytes are included, consisting of a shoot and a root fraction. Further groups in the top layer of the sediment are the settled fractions of the three types of phytoplankton as well as zoobenthos. 
The phytoplankton groups differ in their parameter values. It is assumed that the cyanobacteria (for which the filamentous species serve as a model) have a lower maximum growth rate $\left(0.6 \mathrm{~d}^{-1}\right)$ than the diatoms (2.0) and greens (1.5), but also lower loss rates through respiration (0.05 times $\mu_{\max }$ ), settling (maximal $\mathrm{v}_{\text {set }}=$ $0.06 \mathrm{~d}^{-1}$ for cyanobacteria, 0.2 for greens and 0.5 for diatoms) and zooplankton grazing (a factor 6 lower). It is further assumed that the cyanobacteria have a higher phosphorus affinity ( 0.8 vs $\left.0.21 \mathrm{mg}^{-1} \mathrm{~d}^{-1}\right)$ and maximum $\mathrm{P}$ uptake rate ( 0.04 vs $0.01 \mathrm{~g} \mathrm{P} \mathrm{g}^{-1} \mathrm{~d}^{-1}$ ) than the other groups. No differences were assumed for nitrogen uptake. Nutrient limitation of phytoplankton growth has been modelled by the Droop equation. The light dependency of growth is described by a halfsaturation function for the green algae (with $\mathrm{h}=17 \mathrm{~W} \mathrm{~m}^{-2} \mathrm{PAR}$ at $20^{\circ} \mathrm{C}$ ) and a Steele function (including inhibition by high intensities) for the diatoms and cyanobacteria; the latter have been attributed a low $\mathrm{I}_{\text {opt }}\left(13.6 \mathrm{~W} \mathrm{~m}^{-2}\right.$ at $\left.20^{\circ} \mathrm{C}\right)$ to mimic their shade-adapted character. The effect of temperature has been described by optimum functions, with the diatoms having a lower temperature optimum $\left(18^{\circ} \mathrm{C}\right)$ than the others $\left(25^{\circ} \mathrm{C}\right)$ and the cyanobacteria having a stronger temperature dependency than the green algae (Table 1). Finally, the diatoms are the only group that might be limited by silica. The growth limitation functions due to light and temperature on the one hand and by nutrients (the minimum of the functions for $\mathrm{P}, \mathrm{N}$ and possibly $\mathrm{Si}$ ), on the other hand, are multiplied.

Also the growth of the submerged macrophytes is dependent on under-water light, temperature and nutrients in water and pore water. It is assumed that their growing season starts when a critical spring temperature $\left(9^{\circ} \mathrm{C}\right)$ is reached, and ends at a predefined day in autumn. All parameters have been assigned fixed values in the model, but it should be realized that they show a natural variability within groups in reality. Both the water phase and the top layer of the sediment have their own pools of inorganic nutrients and detritus. Besides mass fluxes of dry weight (DW, representing carbon) and nutrients, the model also contains a number of indirect relations between components, such as the impact of fish
Table 1 Temperature (T) functions and parameters in PCLake

\begin{tabular}{|c|c|c|}
\hline Abiotic process & \multicolumn{2}{|c|}{ Temperature coefficient $c_{i}$} \\
\hline Denitrification & 1.07 & \\
\hline Diffusion & 1.02 & \\
\hline $\begin{array}{l}\text { Mineralization } \\
\text { in sediment or } \\
\text { water }\end{array}$ & 1.07 & \\
\hline Nitrification & 1.08 & \\
\hline Reaeration & 1.024 & \\
\hline Sedimentation & 1.01 & \\
\hline $\begin{array}{l}\text { Biotic } \\
\text { component }\end{array}$ & $\begin{array}{l}\text { Optimum } \\
\text { temperature } \\
\mathrm{T}_{\mathrm{opt}, \mathrm{j}}\end{array}$ & $\begin{array}{l}\text { Width around } \\
\text { optimum } \\
\text { temperature } \mathrm{T}_{\text {sigma, }}\end{array}$ \\
\hline Diatoms & $18^{\circ} \mathrm{C}$ & $20^{\circ} \mathrm{C}$ \\
\hline Green algae & $25^{\circ} \mathrm{C}$ & $15^{\circ} \mathrm{C}$ \\
\hline Cyanobacteria & $25^{\circ} \mathrm{C}$ & $12{ }^{\circ} \mathrm{Cl}$ \\
\hline Zooplankton & $25^{\circ} \mathrm{C}$ & $13^{\circ} \mathrm{C}$ \\
\hline Zoobenthos & $25^{\circ} \mathrm{C}$ & $16^{\circ} \mathrm{C}$ \\
\hline $\begin{array}{l}\text { Planktivorous } \\
\text { and } \\
\text { benthivorous } \\
\text { fish }\end{array}$ & $25^{\circ} \mathrm{C}$ & $10^{\circ} \mathrm{C}$ \\
\hline Piscivorous fish & $25^{\circ} \mathrm{C}$ & $10^{\circ} \mathrm{C}$ \\
\hline Macrophytes & $\mathrm{Q}_{10 \text { prod }}=1.2$ & $\mathrm{Q}_{10 \mathrm{resp}}=2.0$ \\
\hline
\end{tabular}

For abiotic process (i) an exponential function with parameter $c_{i}$ is used: $f_{i}(T)=c_{i}(T-T r e f)$ For biotic component (j), a Gaussian function with parameters $\mathrm{T}_{\text {opt,j }}$ and $\mathrm{T}_{\text {sigma,j }}$ is used: $\mathrm{f}_{\mathrm{j}}(\mathrm{T})=\exp \left(-0.5\left(\mathrm{~T}-\mathrm{T}_{\text {opt }, \mathrm{j}}\right)^{2}-\right.$ $\left.\left(\mathrm{T}-\mathrm{T}_{\text {ref }}\right)^{2} / \mathrm{T}_{\text {sigma,j }}\right)$. In all functions a reference temperature $\mathrm{T}_{\text {ref }}$ of $20^{\circ} \mathrm{C}$ was used. For macrophytes, also an optimum function was used, implemented by two exponential functions with a higher $\mathrm{Q}_{10}$ for respiration $\left(\mathrm{Q}_{10 \mathrm{resp}}\right)$ than for production $\left(\mathrm{Q}_{10 \mathrm{prod}}\right)$. The temperature threshold for macrophyte growth was $9^{\circ} \mathrm{C}$

and macrophytes on resuspension. The overall nutrient cycles of $\mathrm{N}, \mathrm{P}$ and $\mathrm{Si}$ are completely covered by the model, including external fluxes such as in- and outflow and denitrification. This does not hold for carbon because inorganic carbon in the water or sediment is not explicitly modelled. A particularly interesting stoichiometric consequence of modelling the $\mathrm{N}, \mathrm{P}, \mathrm{Si}$ and DW dynamics separately is that the nutrient-todry-weight ratios are thus variable. The main inputs to the model are: water inflow, infiltration or seepage rate, nutrient (N, P) loading, particulate loading, temperature and light, dimensions (lake depth and size), size of the marsh zone, sediment features and loading history (initial conditions). As output, the biomass and concentrations of all state variables, as well as a number of derived variables and fluxes, are calculated. 
Previous studies with PCLake (Janse, 1997, 2005) showed that the model behaviour is consistent with the existing evidence that shallow lakes may have two alternative stable states. In the clear-water state macrophytes dominate and in the turbid state phytoplankton dominates (Timms \& Moss, 1984; Jeppesen et al., 1990; Scheffer, 1990, 1998). Several factors determine which state prevails in a certain case. A general constraint is set by the external nutrient loading. At a (very) high loading, only the turbid state is stable, whereas the opposite is true for (very) low loadings. In the intermediate range, both states can exist (in the field even side by side) and switches between states are possible. The model-like examples studied in the field-shows hysteresis as the shift from clear to turbid due to eutrophication occurs at a much higher nutrient loading than the switch back from turbid to clear due to re-oligotrophication through lake restoration $\left(\mathrm{CNL}_{\mathrm{eu}}>\mathrm{CNL}_{\text {oligo }}\right)$. Both states are maintained by a number of self-stabilizing mechanisms that are included in the model. Macrophytes stabilize the clear state, they compete with phytoplankton for nutrients, promote denitrification, reduce resuspension, hamper the feeding of benthivorous fish and promote top-down control of phytoplankton by promoting piscivorous fish. High algal and-especially-cyanobacterial biomasses stabilise the turbid state and hamper macrophyte growth through turbidity. Top-down effects through grazing pressure by zooplankton are reduced, and the bare sediment promotes internal P-loading.

The effect of temperature on the various model components is entered through a set of fourteen temperature dependent multipliers. Six of these modify abiotic processes: diffusion, sedimentation of particulate matter (only slightly affected), nitrification, denitrification and mineralization in the water phase and the sediment. These have the shape of simple exponential curves. The remaining eight modifiers that amend the growth rates of biotic components of the model are implemented as Gaussian curves around a certain optimum temperature. The model has such curves for the three phytoplankton groups (diatoms, greens and cyanobacteria), zooplankton, zoobenthos, planktivorous fish and piscivorous fish. For macrophytes, also an optimum function was used, implemented by two exponential functions with a higher $\mathrm{Q}_{10}$ for respiration than for production. All the functions and parameters of the temperature curves in PCLake are given in Table 1.

We focused on asymptotic model behaviour (running 25 years with the same input) for a range of temperatures and loading scenarios in a factorial design. To maintain a focus on alternative stable states and critical nutrient loadings each scenario was evaluated twice, starting from either a macrophyte-dominated clear state or a phytoplankton-dominated turbid state. The other model parameters were kept constant and chosen such that they represent an average for shallow lakes in the Netherlands (following Janse, 2005, p. 99). Its main characteristics are: mean depth $=$ $2 \mathrm{~m}$, fetch $=1000 \mathrm{~m}$, areal hydraulic loading = $20 \mathrm{~mm} \mathrm{~d}^{-1}\left(=7.2 \mathrm{~m} \mathrm{y}^{-1}\right)$, no infiltration or seepage, no surrounding wetland zone, and a slightly clayish sediment $(30 \%$ dry matter, of which $10 \%$ is organic and $90 \%$ inorganic matter, the latter containing $10 \%$ lutum).

Phosphorus loading varied within a range of 0.1-20 mg $\mathrm{P} \mathrm{m}^{2} \mathrm{~d}^{-1}$ in 40 steps. The nitrogen loading was set to 10 times the phosphorus loading. We used a sine function with a maximum on July 31 to represent the typical temperature profile of a shallow lake in the Netherlands. In the control scenario (denoted as $\mathrm{C}$ ) the minimum winter temperature was $2^{\circ} \mathrm{C}$ and the summer maximum $22^{\circ} \mathrm{C}$ (Fig. 1). We defined three scenarios with elevated temperatures: an all year round temperature increase of $3^{\circ} \mathrm{C}$ (denoted as $\mathrm{A})$, an increase in summer maximum temperature

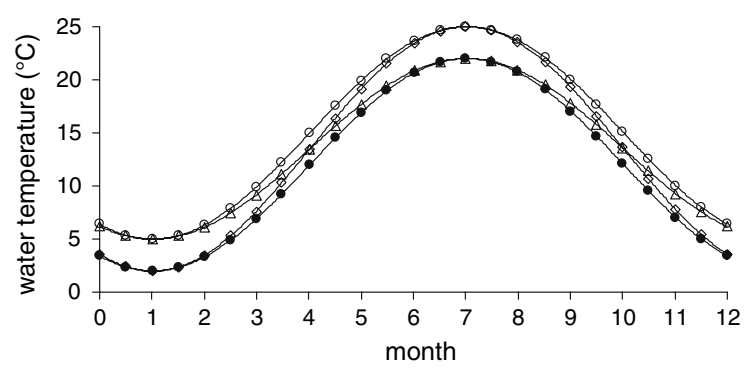

Fig. 1 Temperature patterns for the control (closed circles), all year warm (open circles), warm summer (open diamonds) and warm winter (open triangles) scenario 
of $3^{\circ} \mathrm{C}$ but no change in the winter minimum (denoted as S) and, finally, an increase in winter minimum temperature of $3{ }^{\circ} \mathrm{C}$, but no change in the summer maximum (denoted as $\mathrm{W}$ ).

We focused on the summer averages (from April 1 to September 30) of chlorophyll-a, zooplankton biomass and the percentage of cyanobacteria. This period was chosen because it gives an overall picture of the effects and because this period is used in policy standards. Seasonal deviations are mentioned in the text. For each of the four temperature scenarios (C, A, S and W) we obtained values for the two critical nutrient loadings $\left(\mathrm{CNL}_{\mathrm{eu}}\right.$ and $\left.\mathrm{CNL}_{\text {oligo }}\right)$. To get a more detailed view on lake dynamics we studied within season dynamics of each scenario for nutrient loadings of 0.6 and $4 \mathrm{mg} \mathrm{m}^{2} \mathrm{~d}^{-1}$. Again we focused on total algal and zooplankton biomass and algal community composition.

\section{Results}

The general observation is that climate warming will decrease the critical nutrient loadings. In the control scenario (C) $\mathrm{CNL}_{\text {eu }}$ has a value of $3.3 \mathrm{mg} \mathrm{P} \mathrm{m}^{2} \mathrm{~d}^{-1}$ (Table 2). At this point chlorophyll-a suddenly increases from 10 to $98 \mu \mathrm{g} \mathrm{l^{-1 }}$ (Fig. 2a), total zooplankton biomass increases slightly from 0.62 to $0.85 \mathrm{mg} \mathrm{l}^{-1} \mathrm{DW}$ (Fig 2b), the percentage of cyanobacteria increases from 21 to $79 \%$ (Fig. 2c) and submerged macrophytes virtually disappear (not shown). The model predicts that when environmental temperature is raised by $3^{\circ} \mathrm{C}$ all year (scenario $\mathrm{A}$ ), $\mathrm{CNL}_{\mathrm{eu}}$ decreases by $24 \%$ from 3.3 to $2.5 \mathrm{mg} \mathrm{P} \mathrm{m}^{2} \mathrm{~d}^{-1}$ (Table 2). Raising the winter minimum temperature by $3^{\circ} \mathrm{C}$ (scenario $\mathrm{W}$ ) results in a $12 \%$ decrease in $\mathrm{CNL}_{\mathrm{eu}}$, and raising the summer maximum temperature by $3^{\circ} \mathrm{C}$ (scenario $\mathrm{S}$ ) results in a $18 \%$ decrease in $\mathrm{CNL}_{\mathrm{eu}}$ (Table 2).

The results for $\mathrm{CNL}_{\text {oligo }}$ show a comparable pattern. In the control scenario the switch back takes place at a loading of $0.95 \mathrm{mg} \mathrm{P} \mathrm{m}^{2} \mathrm{~d}^{-1}$ (Table 2). At this point chlorophyll-a suddenly decreases from 44 to $1.5 \mu \mathrm{g} \mathrm{l}^{-1}$ (Fig. 2a), zooplankton biomass decreases slightly from 0.72 to $0.50 \mathrm{mg} \mathrm{l}^{-1} \mathrm{DW}$ (Fig. 2b), cyanobacteria almost completely disappear, decreasing from 68 to $1 \%$ (Fig 2c), and submerged macrophytes become the dominant producers. The model predicts that when environmental temperature is raised by $3^{\circ} \mathrm{C}$ all year (scenario A), $\mathrm{CNL}_{\text {oligo }}$ decreases by ca. $21 \%$ from 0.95 to $0.75 \mathrm{mg} \mathrm{P} \mathrm{m}^{2} \mathrm{~d}^{-1}$ (Table 2). The scenarios in which the summer maximum or the winter minimum is increased by $3^{\circ} \mathrm{C}$ both show a smaller decrease of $10 \%$ in $\mathrm{CNL}_{\text {oligo }}$ (Table 2).

In the clear water state, the effects of the temperature scenarios on chlorophyll-a are insignificant (Fig. 2a). Zooplankton biomass is slightly lower in the temperature scenarios, both in spring and in summer. In the turbid phase, just above the $\mathrm{CNL}_{\mathrm{eu}}$, the model predicts an increase in summer chlorophyll-a from 98 to $133 \mu \mathrm{g}^{-1}$ (Fig. 2a). Zooplankton biomass decreases from 0.85 to $0.61 \mathrm{mg} \mathrm{l}^{-1} \mathrm{DW}$ (Fig. 2b). At intermediate loadings, the strongest decrease of zooplankton is predicted in spring, the period in which also the controls showed a lower biomass in the turbid state than in the clear state. In summer, on the contrary, the model shows a higher zooplankton biomass in the turbid state. The model also predicts that a decrease in zooplankton is generally accompanied by a decrease in juvenile fish. Remarkably, summer warming has the strongest effect on the decrease in critical nutrient loadings, but winter warming has the strongest effect on the

Table 2 Critical nutrient loading $\left(\mathrm{mg} \mathrm{P} \mathrm{m}^{2} \mathrm{~d}^{-1}\right)$ during eutrophication and oligotrophication for the control (C), year round warm (A), warm summer (S) and warm winter (W) scenario

\begin{tabular}{lll}
\hline Temperature scenario & During eutrophication & During oligotrophication \\
\hline Control scenario $\left(\min 2^{\circ} \mathrm{C}, \max 22^{\circ} \mathrm{C}\right)$ & $3.3(10.4$ to 98$)$ & $0.95(44$ to 1.5$)$ \\
All year increase of $3^{\circ} \mathrm{C}$ & $2.5(6.5$ to 133$)$ & $0.75(59$ to 0.5$)$ \\
Increase of $3^{\circ} \mathrm{C}$ in summer maximum & $2.7(6.5$ to 98$)$ & $0.85(40$ to 1.0$)$ \\
Increase of $3^{\circ} \mathrm{C}$ in winter minimum & $2.9(8.5$ to 126$)$ & $0.85(64$ to 1.0$)$ \\
\hline
\end{tabular}

For each scenario the chlorophyll-a concentrations $\left(\mu \mathrm{g} \mathrm{l}^{-1}\right)$ before and after the switch are given in parentheses 

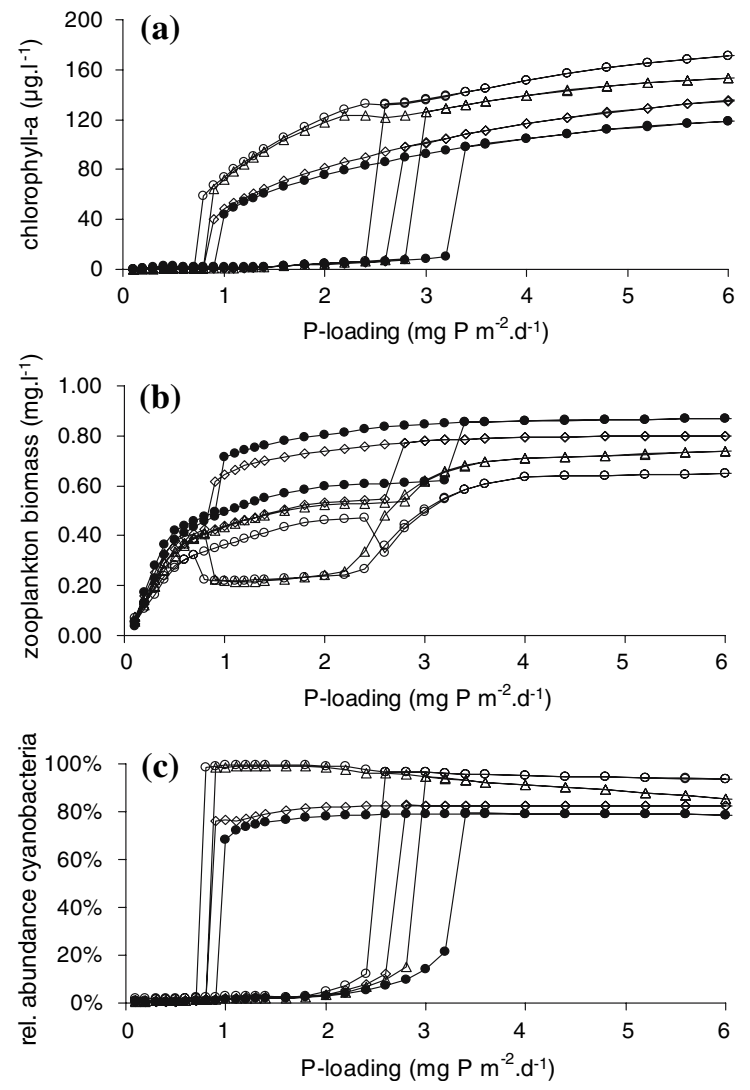

Fig. 2 (a) Average summer chlorophyll-a concentration as a function of nutrient loading for the control (closed circles), all year warm (open circles), warm summer (open diamonds) and warm winter (open triangles) scenario. (b) Zooplankton biomass as a function of nutrient loading for the control (closed circles), all year warm (open circles), warm summer (open diamonds) and warm winter (open triangles) scenario. (c) Percentage of cyanobacteria as a function of nutrient loading for the control (closed circles), all year warm (open circles), warm summer (open diamonds) and warm winter (open triangles) scenario

increase in summer chlorophyll-a (Fig. 2a). Note also that in the case of year round heating or winter heating the increase in chlorophyll-a is strongest at intermediate nutrient loading, in the range where alternative stable states exist (Fig. 2a). The summer-averaged macrophytes biomass is hardly affected by the temperature scenarios.

At an intermediary loading of $2.0 \mathrm{mg} \mathrm{P} \mathrm{m}{ }^{2} \mathrm{~d}^{-1}$ the algal community in the control scenario is composed of ca. $97 \%$ diatoms and only $3 \%$ cyanobacteria in the clear state (Fig 2c). In the turbid state this pattern is reversed to $22 \%$

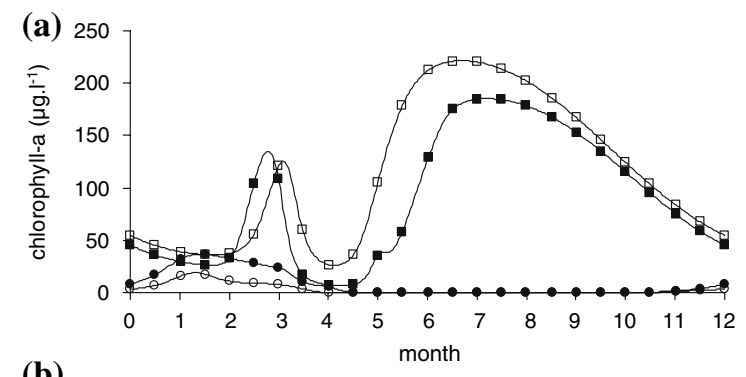

(b)

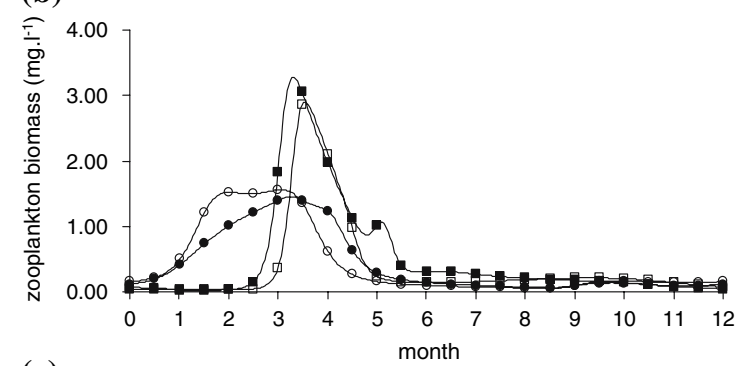

(c)

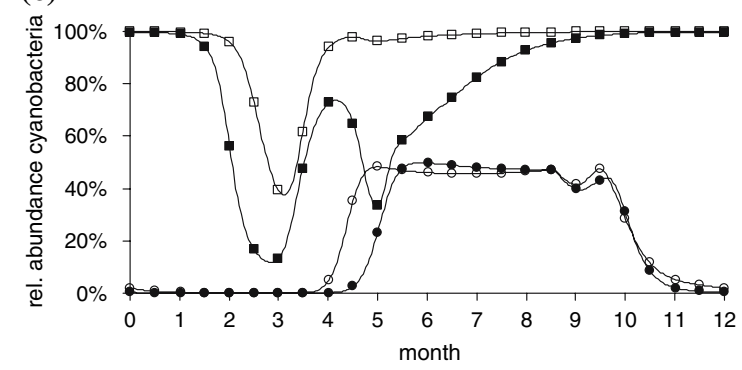

Fig. 3 (a) Chlorophyll-a concentration during the season for the control (closed circles for the clear water state and closed squares for the turbid water state) and all year warm (open circles for the clear water state and open squares for the turbid water state) scenario. (b) Zooplankton biomass during the season for the control (closed circles for the clear water state and closed squares for the turbid water state) and all year warm (open circles for the clear water state and open squares for the turbid water state) scenario. (c) Percentage of cyanobacteria during the season for the control (closed circles for the clear water state and closed squares for the turbid water state) and all year warm (open circles for the clear water state and open squares for the turbid water state) scenario

diatoms and $78 \%$ cyanobacteria (Fig. 2c). Green algae are below $1 \%$ in all simulations (for the lake settings used). In the clear state the temperature scenarios hardly affect phytoplankton community composition (but it must be born in mind, though, that in this case phytoplankton biomass is low compared to submerged macrophytes). In the turbid state, however, in the A-scenario the percentage of cyanobacteria increases from $78 \%$ to an almost complete dominance of $99 \%$ 
(Fig 2c). This happens also in the winter warming scenario. The summer scenario hardly shows any response in cyanobacterial dominance and resembles the control scenario (Fig 2c).

There are large differences in the seasonal patterns between the clear and the turbid state. For the control scenario the model predicts the following patterns: in the clear water state chlorophyll-a starts to build up as early as in February, reaching a peak of about $35 \mu \mathrm{g} \mathrm{l}^{-1}$, which lasts for about 2 months (Fig. 3a) and is strongly dominated by diatoms (Fig 3c). Zooplankton appear in large numbers about one month after the start of the diatom bloom and reach a level of about $1.5 \mathrm{mg} \mathrm{l}^{-1} \mathrm{DW}$ during March and April (Fig 3b). In the clear water state phytoplankton and zooplankton stay low for the rest of the year. In the turbid state the cyanobacteria biomass is relatively high at the onset, a remnant from the year before (Fig. 3a). An additional diatom peak starts to build up around March, reaching a peak value of $135 \mu \mathrm{g} \mathrm{l}^{-1}$ chlorophyll-a around April 1 (Fig. 3a). Also in the turbid state, the spring diatom peak is followed by a spring peak of zooplankton up to $3 \mathrm{mg} \mathrm{l}^{-1} \mathrm{DW}$ (Fig. $3 \mathrm{~b}$ ). In the turbid state the spring peak of algae (dominated by diatoms) is followed by a long-lasting period in which the phytoplankton is dominated by cyanobacteria (Fig. 3c). Because these are less edible for zooplankton compared to diatoms, zooplankton abundance stays low after the spring peak (Fig. 3b).

The all year warming scenario (A) results in an earlier occurrence-approx. 3 weeks-of the spring diatom bloom and zooplankton peak in the clear water state (Fig. 3a, b). In the clear water state the height of the spring diatom peak under all year warming is lower (Fig. 3a, c) because in this scenario they are more effectively grazed upon by the zooplankton whose population builds up faster (Fig 3b). In the turbid state scenario $\mathrm{A}$ results in a higher cyanobacterial biomass during winter and spring, and a slight delay of the diatom and zooplankton peak by approx. a week and a half (Fig. 3a-c). The summer peak in chlorophyll-a in the turbid state is predicted to occur about 1 month earlier (Fig. 3a). Looking at the turbid state, the diatom and zooplankton spring peaks in the all year warming scenario are slightly lower, but the summer phytoplankton peak is considerably higher in A (Fig. 3a, b). The chlorophyll-a concentration during the 'clear water phase', occurring around May, is considerably higher in the all year warm scenario; the 'clear water phase' is therefore less pronounced. There is also a shift in phytoplankton composition during summer for all year warming (Fig. 3c). In the control scenario diatoms make up half of the algal community, but in the all year warming scenario cyanobacteria dominate the algal community from early summer and onwards.

\section{Discussion}

The main conclusion based on the model results is that climate warming will lead to lower critical nutrient loadings. Several mechanisms in the model together are responsible for this effect, mainly the higher growth rate of phytoplankton, especially cyanobacteria, and the increased $\mathrm{P}$ availability due to higher mineralization and release resulting from higher temperatures. The critical nutrient level for eutrophication $\left(\mathrm{CNL}_{\mathrm{eu}}\right)$ as predicted by the model is basically determined by the turbidity level at which the net algal growth (growth minus losses) exceeds the net macrophytes growth, under clear starting conditions. Likewise, $\mathrm{CNL}_{\text {oligo }}$ relies on the transparency level at which net macrophytes growth starts to exceed net algal growth, under turbid starting conditions. Phytoplankters, as opposed to macrophytes, are the first to profit from both the higher water temperatures and the higher $\mathrm{P}$ availability, especially cyanobacteria that also have a high $\mathrm{P}$ affinity and a 'steeper' temperature function. The zooplankton and fish growth rates increase as well due to the temperature rise, but this does not affect the critical $\mathrm{P}$ levels very much. According to the model increased temperatures in winter and early spring have the greatest impact on shallow lake ecosystems, since results from the "warm winter" scenario closely resembled the "year round warm" scenario. By contrast, the "warm summer" scenario yielded results similar to the control scenario. The combination of the predicted lower critical nutrient loading and the anticipated 
increase in external loading implies that in the future some (restored) lakes that are now in the clear state will return to the turbid state. For lakes in the turbid state this means that the nutrient loading has to be reduced to even lower values to generate a switch back to the clear state.

According to the model, chlorophyll-a and dominance of cyanobacteria during summer will increase, winter temperatures being the crucial factor. In the model, again, this result is due to improved growing conditions for cyanobacteria at elevated temperatures. Because of the poor edibility of cyanobacteria, higher trophic levels do not profit from this enhanced carrying capacity at the level of primary producers. The model suggests a reduction of food transfer to the higher trophic levels, mainly in the pelagic (via zooplankton) and a little in the sediment (via zoobenthos), at higher temperatures. On the other hand, from natural systems there are indications that zooplanktivorous fish density may be higher in warmer years (e.g. Jeppesen et al., 2003) and thus impose a higher predation pressure on the zooplankton. The fact that the model emphasizes the bottom up effects of reduced transfer efficiency but not the top-down effects of increased zooplanktivory might imply that the model assumptions on the diet and the mortality of fish are too crude. Elevated winter temperatures seem to be critical for cyanobacteria dominance in shallow systems (Moed \& Hoogveld, 1982; Adrian et al., 1995; Reeders et al., 1998). The predicted increased dominance of cyanobacteria implies that water quality problems in turbid lakes may intensify.

The model predicts that in the clear state the algal (diatom) and zooplankton spring peaks occur earlier, but that in the turbid state these peaks occur later as a result of temperature rise. In the clear state, diatoms start to grow earlier in spring at higher temperature and enhanced $\mathrm{P}$ release. In spring macrophytes are not yet so important, but increase in abundance later in the season when they benefit from the higher temperature and also from the higher $\mathrm{P}$ availability in the sediment. At this point the diatoms do no longer profit from the elevated temperatures, assuming that their optimum is $18^{\circ}$ (compared to $25^{\circ} \mathrm{C}$ for the modelled cyanobacteria). For the clear state this model result is consistent with empirical findings for temperate lakes which showed earlier peaks of phytoplankton and zooplankton at increasing temperatures (Weyhenmeyer et al., 1999; Gerten \& Adrian, 2000; Straile, 2000; Scheffer et al., 2001). The very early timing of both peaks in our scenarios (even in the control as early as February and March, respectively) likely results from the sine function applied for temperature. Note also that ice cover was not included our model scenarios (consistent with conditions in the Netherlands) so that the modelled spring plankton development cannot be explained by ice cover as reported for other systems (Adrian et al., 1999; Livingstone \& Dokulil, 2001). Similar to model result for the clear state, experiments in heated mesocosms suggest that macrophytes remain largely unaffected by moderate warming (McKee et al., 2002b).

For the turbid state the result that phytoplankton and zooplankton peaks are delayed at higher temperatures is somewhat unexpected. Here, cyanobacteria whose densities are already high early in the year (remnants of the summer peak of the year before) profit most from increased temperatures. Despite their increased growth rate in spring, diatoms are poorer competitors and peak later. Since zooplankton mostly rely on edible phytoplankton (diatoms or greens) as a food item they show a delayed development, too. It is difficult to find empirical evidence for the model results on turbid state as virtually all published data on climate effects on plankton phenology stem from less eutrophic and mostly deeper systems. From the study by Scheffer et al. (2001), which exclusively included shallow Dutch lakes, it seems that the general pattern found in other lakes (earlier peaks of phytoplankton and zooplankton at higher temperatures) was confirmed. It is unclear, however, if the pattern would change if only data from turbid lakes were included in such a correlation analysis. In the moderately shallow Heiligensee (average and maximum depth of 5.9 and $9.5 \mathrm{~m}$, respectively) phytoplankton peaks during a warm winter period developed earlier and the contribution of cyanobacteria to the phytoplankton community 
was larger compared to colder years (Adrian et al., 1995). It was suggested that this shift in phytoplankton composition resulted in the replacement of $D$. galeata by the smaller species D. cucullata, the latter species being less adversely affected by the presence of cyanobacteria (Adrian \& Deneke, 1996). Looking at the total abundance patterns of all Daphnia species in that study (Fig. 5 in Adrian \& Deneke, 1996) the displayed peaks indeed seem to occur later during warmer years (with a higher share of cyanobacteria) compared to the colder period. This finding, however, could also be due to species-specific temperature responses and additionally, altered top-down effects seem possible. It is thus unclear whether the result obtained by PCLake - spring diatom and zooplankton peaks in turbid lakes are delayed at increasing temperatures - represents a mechanism also to be found in nature.

We conclude that the analysis performed with PCLake supports the idea that climate change will negatively affect the transparency of temperate shallow lakes (Jeppesen et al., 2003; Mooij et al., 2005). In the first place, climate change is expected to lead to increased external loading. Second, the model predicts that the critical nutrient load during eutrophication will decrease. Together, this will increase the probability that a lake switches from the clear to the turbid state. Third, according to the model's prediction the turbid state will become even more turbid due to a higher summer chlorophyll-a concentration, stronger summer dominance of cyanobacteria and reduced abundance of zooplankton due to climate change. The model provides a consistent view of the chain of effects by which increased nutrient loading and increased temperature may entail the described effects, although the impacts on the food web are possibly over-simplified in the model. Further, climate-related factors such as wind and insolation were neglected in this approach, but theoretically could outweigh temperature effects on, e.g., cyanobacteria dominance. In future scenarios to be explored using coupled physical-biological ecosystem models these factors should be included to further deepen our understanding of climate impacts on aquatic ecosystems.
Acknowledgments We thank Marten Scheffer, Eric Jeppesen and an anonymous reviewer for comments on this manuscript. LdSD was funded by the NWO programme Biodiversity in relation to Global Change (NWO GRANT 852.00.010 / 852.00.012).

\section{References}

Adrian, R. \& R. Deneke, 1996. Possible impact of mild winters on zooplankton succession in eutrophic lakes of the Atlantic European area. Freshwater Biology 36: 757-770.

Adrian, R., R. Deneke, U. Mischke, R. Stellmacher \& P. Lederer, 1995. A long-term study of the Heiligensee (1975-1992). Evidence for effects of climatic change on the dynamics of eutrophied lake ecosystems. Archiv für Hydrobiologie 133: 315-337.

Adrian, R., N. Walz, T. Hintze, S. Hoeg \& R. Rusche, 1999. Effects of ice duration on plankton succession during spring in a shallow polymictic lake. Freshwater Biology 41: 621-632.

Aldenberg, T., J. H. Janse \& P. R. G. Kramer, 1995. Fitting the dynamic model PCLake to a multi-lake survey through Bayesian statistics. Ecological Modelling 78: 83-99.

Barko, J. W. \& R. M. Smart, 1981. Comparative influences of light and temperature on the growth and metabolism of selected submersed fresh-water macrophytes. Ecological Monographs 51: 219-235.

Dawidowicz, P., Z. M. Gliwicz \& R. D. Gulati, 1988. Can Daphnia prevent a blue-green algal bloom in hypertrophic lakes? A laboratory test. Limnologica (Berlin) 19: 21-26.

Drenner, R. W. \& K. D. Hambright, 1999. Review: biomanipulation of fish assemblages as a lake restoration technique. Archiv für Hydrobiologie 146: 129165.

Elliott, J. A., S. J. Thackeray, C. Huntingford \& R. G. Jones, 2005. Combining a regional climate model with a phytoplankton community model to predict future changes in phytoplankton in lakes. Freshwater Biology 50: 1404-1411.

Gerten, D. \& R. Adrian, 2000. Climate-driven changes in spring plankton dynamics and the sensitivity of shallow polymictic lakes to the North Atlantic Oscillation. Limnology and Oceanography 45: 1058-1066.

Gerten, D. \& R. Adrian, 2001. Differences in the persistency of the North Atlantic Oscillation signal among lakes. Limnology and Oceanography 46: 448-455.

Gerten, D. \& R. Adrian, 2002 Effects of climate warming, North Atlantic Oscillation, and El Nino-Southern Oscillation on thermal conditions and plankton dynamics in northern hemispheric lakes. TheScientific WorldJournal 2: 586-606.

Gliwicz, Z. M. \& W. Lampert, 1990. Food thresholds in Daphnia species in the absence and presence of bluegreen filaments. Ecology 71: 691-702.

Gulati, R. D., K. Siewertsen \& G. Postema, 1982. The zooplankton: its community structure, food and 
feeding, and role in the ecosystem of Lake Vechten. Hydrobiologia 95: 127-163.

Gulati, R. D. \& E. Van Donk, 2002. Lakes in the Netherlands, their origin, eutrophication and restoration: state-of-the-art review. Hydrobiologia 478: 73106.

Houghton J. T., Y. Ding, D. J. Griggs, M. Noguer, P. J. Van der Linden \& D. Xiaosu (eds), 2001. Climate Change 2001: The Scientific Basis. Contribution of Working Group I to the Third Assessment Report of the Intergovernmental Panel on Climate Change (IPCC). Cambridge University Press, Cambridge: $944 \mathrm{pp}$.

Howard, A. \& M. P. Easthope, 2002. Application of a model to predict cyanobacterial growth patterns in response to climatic change at Farmoor Reservoir, Oxfordshire, UK. Science of the Total Environment 282: 459-469.

Janse, J. H., 1997. A model of nutrient dynamics in shallow lakes in relation to multiple stable states. Hydrobiologia 342/343: 1-8.

Janse, J. H., 2005. Model studies on the eutrophication of shallow lakes and ditches, Wageningen University.

Janse, J. H., T. Aldenberg \& P. R. G. Kramer, 1992. A mathematical model of the phosphorus cycle in Lake Loosdrecht and simulation of additional measures. Hydrobiologia 233: 119-136.

Janse, J. H. \& L. Van Liere, 1995a. Modelling nutrient cycles in relation to food-web structure in a biomanipulated shallow lake. Netherlands Journal of Aquatic Ecology 29: 67-79.

Janse, J. H. \& L. Van Liere, 1995b. PCLake - a modeling tool for the evaluation of lake restoration scenarios. Water Science and Technology 31: 371-374.

Jensen, H. S. \& F. O. Andersen, 1992. Importance of temperature, nitrate, and $\mathrm{pH}$ for phosphate release from aerobic sediments of four shallow, eutrophic lakes. Limnology and Oceanography 37: 577-589.

Jeppesen, E., J. P. Jensen, M. Sondergaard, K. S. Hansen, P. H. Moller, H. U. Rasmussen, V. Norby \& S. E. Larsen, 2003. Does resuspension prevent a shift to a clear state in shallow lakes during reoligotrophication? Limnology and Oceanography 48: 1913-1919.

Jeppesen, E., M. Sondergaard, E. Mortensen, P. Kristensen, B. Riemann, H. J. Jensen, J. P. Müller, O. Sortkjaer, J. P. Jensen, K. Christoffersen, S. Bosselmann \& E. Dall, 1990. Fish manipulation as a lake restoration tool in shallow, eutrophic temperate lakes 1: cross-analysis of three Danish case studies. Hydrobiologia 200/201: 205-218.

Kilham, S. S., E. C. Theriot \& S. C. Fritz, 1996. Linking planktonic diatoms and climate change in the large lakes of the Yellowstone ecosystem using resource theory. Limnology and Oceanography 41: 1052-1062.

Liboriussen, L., F. Landkildehus, M. Meerhoff, M. E. Bramm, M. Sondergaard, K. Christoffersen, K. Richardson, T. L. Lauridsen \& E. Jeppesen, 2005. Global warming: design of a flow-through shallow lake mesocosm climate experiment. Limnology and Oceanography Methods 3: 1-9.
Liikanen, A., T. Murtoniemi, H. Tanskanen, T. Vaisanen \& P. J. Martikainen, 2002. Effects of temperature and oxygen availability on greenhouse gas and nutrient dynamics in sediment of a eutrophic mid-boreal lake. Biogeochemistry 59: 269-286.

Livingstone, D. M. \& M. T. Dokulil, 2001. Eighty years of spatially coherent Austrian lake surface temperatures and their relationship to regional air temperature and the North Atlantic Oscillation. Limnology and Oceanography 46: 1220-1227.

McKee, D., D. Atkinson, S. Collings, J. Eaton, I. Harvey, T. Heyes, K. Hatton, D. Wilson \& B. Moss, 2002a. Macro-zooplankter responses to simulated climate warming in experimental freshwater microcosms. Freshwater Biology 47: 1557-1570.

McKee, D., D. Atkinson, S. E. Collings, J. W. Eaton, A. B. Gill, I. Harvey, K. Hatton, T. Heyes, D. Wilson \& B. Moss, 2003. Response of freshwater microcosm communities to nutrients, fish, and elevated temperature during winter and summer. Limnology and Oceanography 48: 707-722.

McKee, D., K. Hatton, J. W. Eaton, D. Atkinson, A. Atherton, I. Harvey \& B. Moss, 2002b. Effects of simulated climate warming on macrophytes in freshwater microcosm communities. Aquatic Botany 74: $71-83$.

Mehner, T., H. Dörner \& H. Schultz, 1998. Factors determining the year-class strength of age-0 Eurasian perch (Perca fluviatilis, L.) in a biomanipulated reservoir. Archiv of Fisheries and Marine Research 46: 241-251.

Moed, J. R. \& H. L. Hoogveld, 1982. The algal periodicity in Tjeukemeer during 1968-1978. Hydrobiologia 95: 223-224.

Mooij, W. M., 1996. Variation in abundance and survival of fish larvae in shallow eutrophic lake Tjeukemeer. Environmental Biology of Fishes 46: 265-279.

Mooij, W. M., S. Hülsmann, L. N. De Senerpont Domis, B. A. Nolet, P. L. E. Bodelier, P. C. M. Boers, M. L. Dionisio Pires, H. J. Gons, B. W. Ibelings, R. Noordhuis, R. Portielje, K. Wolfstein \& E. H. R. R. Lammens, 2005. The impact of climate change on lakes in the Netherlands: a review. Aquatic Ecology 39: 381-400.

Mooij, W. M. \& E. H. Van Nes, 1998. Statistical analysis of the somatic growth rate of $0+$ fish in relation to temperature under natural conditions. Canadian Journal of Fisheries and Aquatic Sciences 55: 451-458.

Moss, B., D. McKee, D. Atkinson, S. E. Collings, J. W. Eaton, A. B. Gill, I. Harvey, K. Hatton, T. Heyes \& D. Wilson, 2003. How important is climate? Effects of warming, nutrient addition and fish on phytoplankton in shallow lake microcosms. Journal of Applied Ecology 40: 782-792.

Nyberg, P., E. Bergstrand, E. Degerman \& O. Enderlein, 2001. Recruitment of pelagic fish in an unstable climate: studies in Sweden's four largest lakes. AMBIO 30: 559-564.

Pace, M. L., 1984. Zooplankton community structure, but not biomass, influences the phosphorus-chlorophyll a 
relationship. Canadian Journal of Fisheries and Aquatic Sciences 41: 1089-1096.

Parmesan, C. \& G. Yohe, 2003. A globally coherent fingerprint of climate change impacts across natural systems. Nature 421: 37-42.

Porter, K. G., P. A. Saunders, K. A. Haberyan, A. E. Macubbin, T. R. Jacobsen \& R. E. Hodson, 1996. Annual cycle of autotrophic and heterotrophic production in a small, monomictic Piedmont lake (Lake Oglethorpe): analog for the effects of climatic warming on dimictic lakes. Limnology and Oceanography 41: 1041-1051.

Reeders, H. H., P. C. M. Boers, D. T. Van der Molen \& T. H. Helmerhorst, 1998. Cyanobacterial dominance in the lakes Veluwemeer and Wolderwijd, The Netherlands. Water Science and Technology 37: 85-92.

Rooney, N. \& J. Kalff, 2000. Inter-annual variation in submerged macrophyte community biomass and distribution: the influence of temperature and lake morphometry. Aquatic Botany 68: 321-335.

Scheffer, M., 1990. Multiplicity of stable states in freshwater systems. Hydrobiologia 200/201: 475-486.

Scheffer, M., 1998. Ecology of Shallow Lakes. Chapman \& Hall, London. 357 pp.

Scheffer, M., S. H. Hosper, M. L. Meijer, B. Moss \& E. Jeppesen, 1993. Alternative equilibria in shallow lakes. Trends in Ecology \& Evolution 8: 275-279.

Scheffer, M., S. Rinaldi, Y. A. Kuznetsov \& E. H. Van Nes, 1997. Seasonal dynamics of Daphnia and algae explained as a periodically forced predator-prey system. Oikos 80: 519-532.

Scheffer, M., D. Straile, E. H. Van Nes \& H. Hosper, 2001. Climatic warming causes regime shifts in lake food webs. Limnology and Oceanography 46: 1780-1783.

Schelske, C. L., H. J. Carrick \& F. J. Aldridge, 1995. Can wind-induced resuspension of meroplankton affect phytoplankton dynamics? Journal of the North American Benthological Society 14: 616-630.
Sommer, U., Z. M. Gliwicz, W. Lampert \& A. Duncan, 1986. The PEG-model of seasonal succession of planktonic events in fresh waters. Archiv für Hydrobiologie 106: 433-471.

Straile, D., 2000. Meteorological forcing of plankton dynamics in a large and deep continental European lake. Oecologia 122: 44-50.

Straile, D. \& R. Adrian, 2000. The North Atlantic Oscillation and plankton dynamics in two European lakes - two variations on a general theme. Global Change Biology 6: 663-670.

Timms, R. M. \& B. Moss, 1984. Prevention of growth of potentially dense phytoplankton population by zooplankton grazing in the presence of zooplanktivorous fish, in a shallow wetland ecosystem. Limnology and Oceanography 29: 472-486.

Van de Bund, W. J., S. Romo, M. J. Villena, M. Valentin, E. Van Donk, E. Vicente, K. Vakkilainen, M. Svensson, D. Stephen, A. Stahl-Delbanco, J. Rueda, B. Moss, M. R. Miracle, T. Kairesalo, L. A. Hansson, J. Hietala, M. Gyllstrom, J. Goma, P. Garcia, M. Fernandez-Alaez, C. Fernandez-Alaez, C. Ferriol, S. E. Collings, E. Becares, D. M. Balayla \& T. Alfonso, 2004. Responses of phytoplankton to fish predation and nutrient loading in shallow lakes: a pan-European mesocosm experiment. Freshwater Biology 49: 16081618 .

Van de Bund, W. J. \& E. Van Donk, 2002. Short-term and long-term effects of zooplanktivorous fish removal in a shallow lake: a synthesis of 15 years of data from Lake Zwemlust. Freshwater Biology 47: 2380-2387.

Weyhenmeyer, G. A., T. Blenckner \& K. Pettersson, 1999. Changes of the plankton spring outburst related to the North Atlantic Oscillation. Limnology and Oceanography 44: 1788-1792.

Winder, M. \& D. E. Schindler, 2004. Climate change uncouples trophic interactions in an aquatic ecosystem. Ecology 85: 2100-2106. 